Brit. J. vener. Dis. (1956), 32, 34.

\title{
EXPERIMENTAL STUDIES TO DEVELOP LOCAL PROPHYLACTIC AGENTS AGAINST SYPHILIS*
}

\author{
BY \\ R. C. ARNOLD \\ Technical Services Branch, National Heart Institute, National Institute of Health, Washington, D.C. \\ AND \\ JOHN C. CUTLER \\ Bureau of State Services, Washington, D.C.
}

In this report a résumé is given of a series of experimental studies carried out in rabbits to develop effective local prophylactic agents against syphilis transmitted by application of a spirochaetal emulsion to the penile mucous membrane (Table). These studies were made at the Venereal Disease Research Laboratory of the United States Public Health Service between 1941 and 1946.

The development and composition of the most effective agent, Mapharsen ( $0 \cdot 2$ per cent.) in a 1 per cent. aqueous solution of alkyl aryl sulphate, has already been reported (Arnold and Mahoney, 1948). However, a large number of compounds were screened during the search, and no formal report has yet been made of the findings.

The widespread use of prophylactic agents might be found desirable and necessary in the event of some future widespread mobilization. Also, in areas of high prevalence of chancroid, the armed services still might find desirable a local prophylactic agent effective against syphilis, gonorrhoea, and chancroid. Since the search for an effective agent against all three diseases should logically be based upon attempts to incorporate an effective antichancroid agent into a preparation which has already been found effective against syphilis and gonorrhoea both in vivo and in vitro (Arnold and Mahoney, 1948 ; Funes and Aguilar, 1952), it was thought desirable to give in some detail the results of the various studies which determined the efficacy of this preparation.

In the course of these experimental studies, it was kept in mind that the desirable prophylactic preparation was one which would be simple to use, aesthetically acceptable, and not painful to the

* Received for publication September 21, 1955. individual (in contrast to the calomel-sulphathiazole ointment widely used as a prophylactic agent). It was thought that the preparation should preferably be an aqueous solution which could be prepared from an easily transported powder immediately after the potentially infective contact, and which would be made part of the routine of washing for cleansing purposes after contact. Thus, the agent should be cleansing, preferably lathering, deodorant, therapeutically effective against syphilis, gonorrhoea, and chancroid if possible, and not likely to produce contact dermatitis.

The details of testing the various preparations in rabbits have been described in earlier publications (Arnold and Mahoney, 1948; Mahoney, 1936). They may be summarized by stating that an emulsion of Treponema pallidum (Nichols strain) prepared from testes of rabbits with syphilitic orchitis, was applied for periods of 1 or $2 \mathrm{hrs}$ to the intact mucosa of the penis and preputial sac of adult male rabbits. In these experiments, healthy rabbits of the chinchilla breed were used. The emulsion was applied to a small cotton pledget which was placed in the preputial sac and moistened with the emulsion every 15 to $20 \mathrm{~min}$. Following exposure, a control group of rabbits was segregated. The remaining animals were treated prophylactically either by application to the mucosa of the agent to be tested or by systemic administration. The animals were examined at regular intervals to record the development of a penile chancre, the specificity of which was determined by dark-field examination. Proof of lack of development of infection or of asymptomatic infection was determined by lymph-node transfer of all animals showing no clinical evidence of infection within 140 days 
TABLE

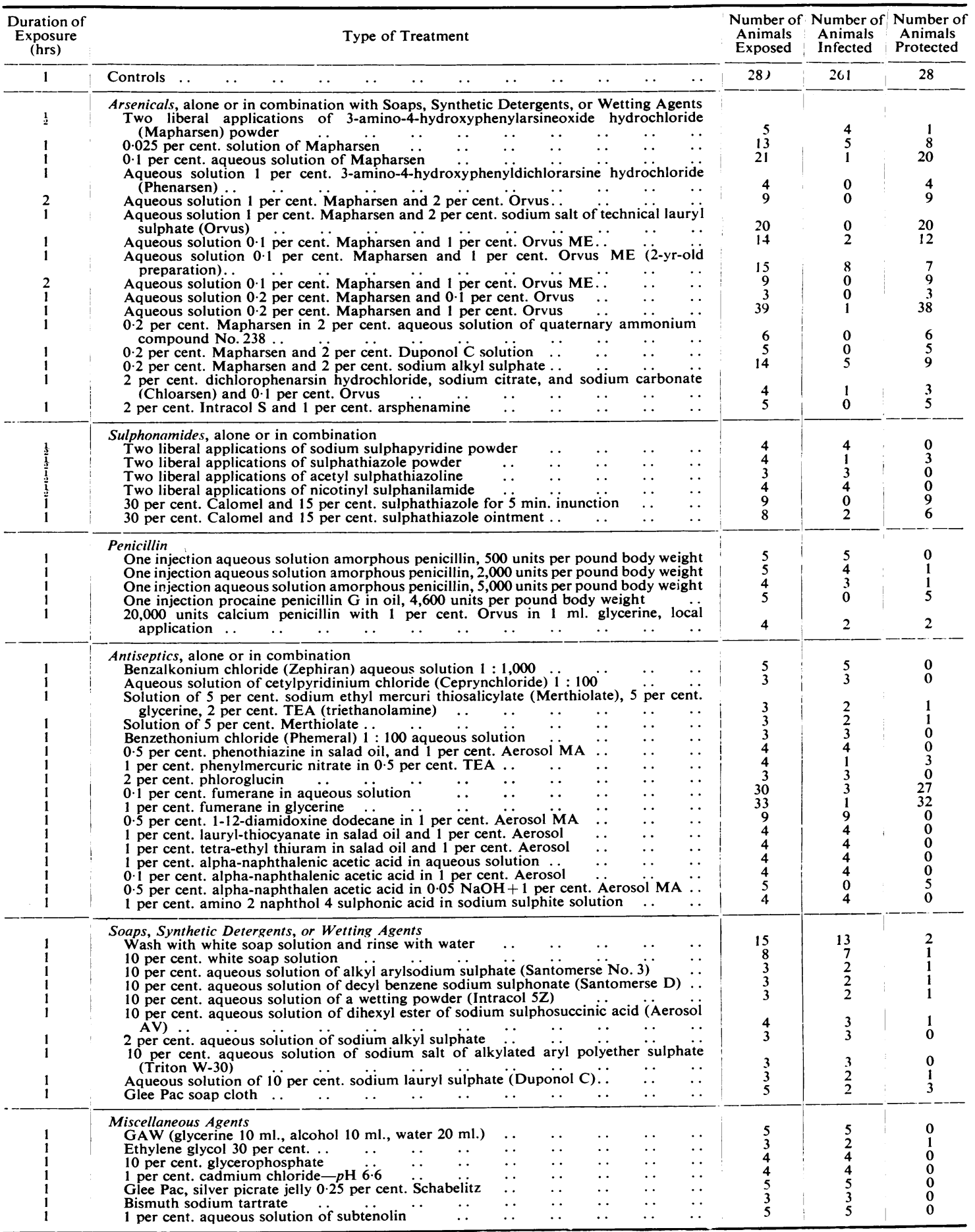


after exposure. Observations lasted an additional 100 days in cases of gland transfer.

It should be added that there were no diagnostic or evaluation problems introduced in this study by $T$. cuniculi. This organism, a normal inhabitant of the rabbit preputial mucous membrane, produces, if any, a lesion which is different from that of syphilis (McLeod and Turner, 1946), in fact, it can only be made to produce a lesion with any degree of certainty under special experimental conditions.

\section{Summary}

Experimental studies of the effectiveness of various agents in local or systemic prophylaxis against syphilis are reported. No attempt has been made to determine the relative effectiveness of the prophylactic preparations tested but the high degree of effectiveness of locally applied solutions of OrvusMapharsen and of solutions of Fumerane, or of parenteral penicillin, is indicated.

The Table, which lists the prophylactic agents, including combinations of preparations, shows the number of animals protected in relation to those exposed for various intervals of exposure.

\section{REFERENCES}

Arnold, R. C., and Mahoney, J. F. (1948). J. vener. Dis. Inform., 29, 138.

Funes, J. M., and Aguilar, C. L. (1952). Bol. Ofic. sanit. pan-amer., $33,121$.

Mahoney, J. F. (1936). Milit. Surg., 78, 351.

McLeod, C., and Turner, T. B. (1946). Amer. J. Syph., 30, 442. 